\title{
Editorial to Consensus Guidelines for Therapeutic Drug Monitoring in Neuropsychopharmacology
}

\author{
Author \\ Gerhard Gründer
}

\author{
Correspondence \\ Prof. Gerhard Gründer, MD \\ Uniklinik RWTH Aachen \\ Department of Psychiatry, \\ Psychotherapy and Psychosomatics \\ Pauwelsstr. 30 \\ 52074 Aachen \\ Germany \\ ggruender@ukaachen.de
}

This issue of Pharmacopsychiatry contains only one major paper, the Consensus Guidelines for Therapeutic Drug Monitoring in Neuropsychopharmacology: Update 2017 by Hiemke et al. [1] and an accompanying invited commentary by de Leon [2]. The consensus guidelines are published by the task force "Therapeutic Drug Monitoring" (TDM) of the Arbeitsgemeinschaft für Neuropsychopharmakologie und Pharmakopsychiatrie" (AGNP), of which Pharmacopsychiatry is the official organ. The first consensus guidelines for TDM were published in 2004, led by the task force's first chairman Pierre Baumann [3]. Christoph Hiemke followed Pierre Baumann as the chairman of the task force, and he was also the lead author of the first update of the consensus guidelines published in 2011 [4]. According to the Web of Science (ISI Web of Knowledge), as of July $30^{\text {th }}, 2017$, the first consensus was cited 311 times, and the 2011 update 387 times. Thus, the consensus guidelines represent highly influential papers in the field of psychopharmacology, and the new update due to its encyclopaedic nature will most likely even top its predecessors.

Interestingly, while "individualization" or "personalization" of treatment is a top priority on the research agenda of most psychiatric scientific societies, TDM is indeed the only clinically proven approach for personalized treatment in psychiatry. This is in sharp contrast to the fact that - although cheap and widely available TDM is not systematically established in routine patient care. While the translation of a tremendous amount of knowledge about the biological bases of mental disorders, which has been accumulated over the last half century, into clinical practice is at best insufficient, and with industry research in psychopharmacology that has fo- cused on the development of new compounds being more or less unsuccessful, huge numbers of patients would benefit from improvement of treatment with the drugs that are already available. TDM and pharmacogenetics, the latter being tightly linked to the former, because drug plasma levels are strongly determined by genotypes of drug metabolizing enzymes, represent tools that substantially increase the safety of treatment with psychotropic drugs and that enhance treatment response. While several influential commissions and consortia such as the "Clinical Pharmacogenetics Implementation Consortium (CPIC)" [5] and the German "Commission on Genetic Testing (GEKO)" [6] recently published recommendations on how to integrate and implement pharmacogenetics and dosing recommendations based on CYP2D6 and/or CYP2C19 genotype into clinical routine towards personalized medicine, such guidelines are mostly ignored by clinicians and are far from application to routine patient management. Jose de Leon in his commentary on the new consensus guidelines [2, in this issue] points out that TDM has been widely neglected by US psychiatry, because it has speculated for decades on the pharmacodynamics of psychotropic drugs - which is still mostly unknown - and ignored the hard science of pharmacokinetics. The major influence of US on European psychiatry might have substantially influenced the reception of TDM in Europe and elsewhere in the world. I strongly agree with de Leon that it is now the challenging task for the AGNP task force TDM to make the huge amount of knowledge, which has been put together in the new consensus guidelines, digestible for clinicians, and to teach them the science of TDM, pharmacokinetics and pharmacogenetics. 


\section{References}

[1] Hiemke C, Bergemann N, Clement HW et al. Consensus guidelines for therapeutic drug monitoring in neuropsychopharmacology: Update 2017. Pharmacopsychiatry 2018; 51: 9-62

[2] De Leon J. A Critical Commentary on the 2017 AGNP Consensus guidelines for therapeutic drug monitoring in neuropsychopharmacology. Pharmacopsychiatry 2018; 51: 63-68

[3] Baumann P, Hiemke C, Ulrich S et al. The AGNP-TDM expert group consensus guidelines: Therapeutic drug monitoring in psychiatry. Pharmacopsychiatry 2004; 37: 243-265

[4] Hiemke C, Baumann P, Bergemann N et al. AGNP Consensus guidelines for therapeutic drug monitoring in psychiatry: Update 2011.

Pharmacopsychiatry 2011; 44: 195-235
[5] Hicks JK, Bishop JR, Sangkuhl K et al. Clinical Pharmacogenetics Implementation Consortium (CPIC) guideline for cyp2d6 and cyp2c19 genotypes and dosing of selective serotonin reuptake inhibitors. Clin Pharmacol Ther 2015; 98: 127-134

[6] Gendiagnostik-Kommission. Richtlinie der Gendiagnostik-Kommission (GEKO) für die Beurteilung genetischer Eigenschaften hinsichtlich ihrer Bedeutung für die Wirkung eines Arzneimittels bei einer Behandlung gemäß § 23 Abs. 2 Nr. 1b GenDG. Bundesgesundheitsbl 2017; 60: 472-475 (Available from http://www.rki.de/DE/Content/Kommissionen/GendiagnostikKommission/Richtlinien/RL-WirkungArzneimittel.pdf?_blob = publicationFile [Accessed 07/31/2017]) 